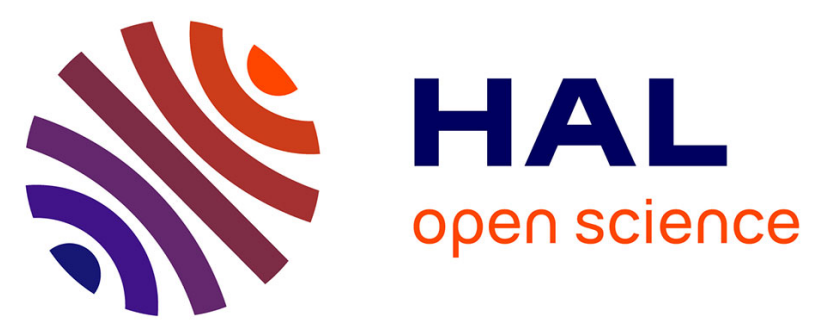

\title{
Correlation between the composition of PLA-based folate targeted micelles and release of phosphonate derivative of betulin
}

Katarzyna Jelonek, Bożena Kaczmarczyk, Arkadiusz Orchel, Ewa Chodurek, Marzena Jaworska - Kik, Piotr Paduszyński, Ewa Bębenek, Elwira Chrobak, Monika Musial-Kulik, Aleksander Foryś, et al.

\section{To cite this version:}

Katarzyna Jelonek, Bożena Kaczmarczyk, Arkadiusz Orchel, Ewa Chodurek, Marzena Jaworska Kik, et al.. Correlation between the composition of PLA-based folate targeted micelles and release of phosphonate derivative of betulin. Journal of Drug Delivery Science and Technology, 2021, 65, 10.1016/j.jddst.2021.102717 . hal-03369693

\section{HAL Id: hal-03369693 https://hal.science/hal-03369693}

Submitted on 7 Oct 2021

HAL is a multi-disciplinary open access archive for the deposit and dissemination of scientific research documents, whether they are published or not. The documents may come from teaching and research institutions in France or abroad, or from public or private research centers.
L'archive ouverte pluridisciplinaire HAL, est destinée au dépôt et à la diffusion de documents scientifiques de niveau recherche, publiés ou non, émanant des établissements d'enseignement et de recherche français ou étrangers, des laboratoires publics ou privés. 


\section{Correlation between the composition of PLA-based folate targeted micelles and release of phosphonate derivative of betulin}

Katarzyna Jelonek $^{1 *}$, Bożena Kaczmarczyk ${ }^{1}$, Arkadiusz Orchel ${ }^{2}$, Ewa Chodurek ${ }^{2}$, Marzena Jaworska - Kik ${ }^{2}$, Piotr Paduszyński ${ }^{2}$, Ewa Bębenek ${ }^{3}$, Elwira Chrobak ${ }^{3}$, Monika MusiałKulik $^{1}$, Aleksander Foryś ${ }^{1}$, Stanisław Boryczka ${ }^{3}$, Suming $\mathrm{Li}^{4 *}$ and Janusz Kasperczyk ${ }^{2 *}$

${ }^{1}$ Centre of Polymer and Carbon Materials, Polish Academy of Sciences, Curie-Sklodowska 34 St., 41-819 Zabrze, Poland

${ }^{2}$ Faculty of Pharmaceutical Sciences in Sosnowiec, Medical University of Silesia, Katowice, Poland, Department of Biopharmacy, Jedności 8, Sosnowiec, Poland

${ }^{3}$ Faculty of Pharmaceutical Sciences in Sosnowiec, Medical University of Silesia, Katowice, Poland, Department of Organic Chemistry, Jagiellońska 4, Sosnowiec, Poland

${ }^{4}$ Institut Européen des Membranes, IEM, UMR 5635, Univ Montpellier, CNRS, ENSCM, Montpellier, France

* Correspondence: Corresponding authors e-mail addresses: janusz.kasperczyk@sum.edu.pl (J. Kasperczyk), tel.: +48 3227160 77, fax: +48 3227129 69; suming.li@ umontpellier.fr (S. Li), tel: +33 46714 9121; kjelonek@ @mpw-pan.edu.pl (K. Jelonek) tel.: +48 3227160 77, fax: +48322712969. 
Abstract: There are increasing numbers of developed nanocarriers for anticancer drug delivery in the aim to avoid side effects of the conventional chemotherapy. Filomicelles with folic acid (FA) as a targeting moiety are a novel approach that can potentially maximize therapeutic efficacy while minimizing side effects. The aim of this study was to analyze the influence of composition of PLA-based micelles functionalized with folic acid on their drug encapsulation and release properties as well as cytotoxic activity against cancer cells. Micelles were obtained from combination of poly(L-lactide)-Jeffamine-folic acid (PLA-Jeff-FA) and poly(L-lactide)-poly(ethylene glycol) (PLA-PEG) or poly(L-lactide)-poly(ethylene glycol)folic acid and PLA-PEG. E-29-diethoxyphosphoryl-28-O-propynoylbetulin as an anticancer agent was encapsulated into micelles. The in vitro biocompatibility of drug-free micelles was confirmed as well as cytotoxicity of E-29-diethoxyphosphoryl-28-O-propynoylbetulin loaded micelles against FR-positive SK-BR-3 cells. The micelles provided a release of an active agent for over 260 hours. However, the micelles characterized differences in morphology, drug loading and release properties. The hydrophobic block length has been identified as a factor that may be used to control inter- and intramolecular interactions and, in consequence, micelle's properties, e.g. drug encapsulation efficiency and release rate.

Keywords: filomicelles; micelles; PLA-PEG; Jeffamine; folic acid; targeted therapy; betulin derivative 


\section{Introduction}

Cancer is the second leading cause of death worldwide. The serious problem of intravenous systemic chemotherapy is the unspecific targeting to the tumor and difficulties to achieve therapeutic levels of drug within or adjacent to the tumor. Furthermore, significant concentrations of drug frequently accumulate in healthy tissue, leading to severe side effects and dose-limiting toxicity [1]. Nanocarriers may be used for increasing the bioavailability of anticancer drug dosage, especially for poorly soluble drugs [2]. Polymeric micelles have a coreshell structure formed by self-assembly of amphiphilic block copolymers which can solubilize poorly water-soluble anticancer drugs. Among the various shapes of nanocarriers, worm-like micelles (filomicelles) present advantageous properties for enhanced in vivo drug delivery efficiency compared to other morphologies [3]. They possess longer circulation time in the bloodstream and display higher drug loading capacity as compared to spherical micelles [4-6]. Therefore, various drugs have been encapsulated into filomicelles for cancer therapy, e.g. cycloprotoberberine [7], paclitaxel [2, 8] or a combination of several drugs [9]. Filomicelles obtained from polylactide-poly(ethylene glycol) (PLA-PEG) (Fig. 1) have been developed for single or multi-drug delivery [10-12]. Polylactide (PLA) is commonly used as hydrophobic block of amphiphilic copolymers due to its biocompatibility and biodegradability [13]. PLA has been approved by the US Food and Drug Administration (FDA) for medical applications, because their products of degradation are eliminated from the body in the form of carbon dioxide and water [14]. Poly(ethylene glycol) (PEG) is the most commonly used hydrophilic block of self-assembled structures due to its physicochemical and biological properties [15]. PEG modification is generally adopted to prolong the plasma half-life of polymeric carriers by preventing from protein adsorption and cellular adhesion, which minimizes the detection by the immune system. Moreover, nano-size of micelles enables to increase drug accumulation in tumor due to the enhanced permeation and retention (EPR) effect. Additional modification with 
folic acid (FA) may increase retention of the nanocarrier in the tumor and facilitate its uptake through folate receptors (FR) mediated endocytosis, enabling targeting tumor cells more efficiently and precisely [16]. Because of high tumor-specificity, the exploitation of FRtargeted strategies has led to the development of nanomedicines and nanoprobes for chemotherapy and diagnostics. As opposed to antibody-based targeting moieties, FA holds several advantages as a targeting moiety including low molecular weight, non-immunogenicity, relatively high structural stability, and ease of synthesis [16, 17]. FA receptors are overexpressed in several human carcinomas including breast, ovary, endometrium, kidney, lung, head and neck, brain, colon and myeloid cancers while only minimally distributed in normal tissues [18-21]. Among various kinds of drug delivery systems, also micelles targeted with folic acid have been studied [16, 22]. The study is also conducted to develop FA targeted filomicelles that can enter cells by receptor-mediated endocytosis, which can potentially maximize therapeutic efficacy while minimizing side effects. We have reported on the development of FA-targeted filomicelles obtained from the mixture of the newly synthesized and characterized PLA-Jeffamine-FA polymer and PLA-PEG [23]. Jeffamine (Fig. 1) is an amino-terminated polyetheramine composed of poly(propylene oxide) (PPO) and poly(ethylene oxide) (PEO) blocks [24, 25]. Jeffamine has been successfully used in various drug delivery systems, e.g. in nanoparticle decoration [26], thermo-responsive hydrogels for drug delivery [27], thermo-associative nanoparticles for drug delivery [28], preparation of micelles $[24,25]$. The micelles obtained from PLA-PEG/PLA-Jeffamine-FA characterized the prolonged release of anticancer agent, successful in vitro internalization by FR-positive HeLa cell line and cytotoxicity of drug-loaded loaded micelles against anticancer cells [23]. It is also important to note that the Jeffamine ${ }^{\circledR}$ ED used in the synthesis of PLA-Jeffamine-FA has confirmed biocompatibility [29]. This study focuses on the comparison of micelles obtained from mixture of PLA-PEG and PLA-Jeffamine-FA with micelles obtained from PLA-PEG and 
commonly used PLA-PEG-FA micelles. The influence of filomicelles composition on drugpolymer interactions, morphology, cytotoxicity against cancer cells and release of anticancer agent - betulin derivative (E-29- diethoxyphosphoryl-28-O-propynoylbetulin) (Fig. 1) was analyzed.

The use of natural plant-derived compounds has been considered to be an interesting aspect for the treatment of human neoplastic diseases because they are relatively easily available [30, 31]. Betulin has been shown to elicit anticancer properties by inhibiting cancer cell growth. Moreover, a series of new betulin derivatives have been synthesized to improve their cytotoxicity [32-35]. The presence of propynoyloxy group at the C28 position causes an augmentation of cytotoxic responses in several cell lines. Studies on endometrial adenocarcinoma and melanoma cell lines revealed activation of caspase- 3 dependent apoptosis after treatment with 28-O-propynoylbetulin [36-38]. However, the MCF7 breast cancer cell line turned out to be highly resistant to that compound [39]. As continuation of the compound development, we inserted the diethoxyphosphoryl group at C29 position of the acetylenic derivative of betulin. The resultant substance exhibited substantially increased toxicity in several neoplastic cell lines, including breast, ovarian, lung, colon and cervical cancer cell lines as well as leukemia cells. Our results suggested an occurrence of necrotic-like cell death following depolarization of mitochondria, as the consequence of cell treatment with E-29diethoxyphosphoryl-28-O-propynoylbetulin ([35] and unpublished observations). Unfortunately, betulin and its derivatives are highly hydrophobic and poorly soluble in water. Therefore it is of major importance to develop a FA-targeted nanocarrier that can effectively encapsulate phosphonate betulin derivative (E-29-diethoxyphosphoryl-28-Opropynoylbetulin; ECH147B). 

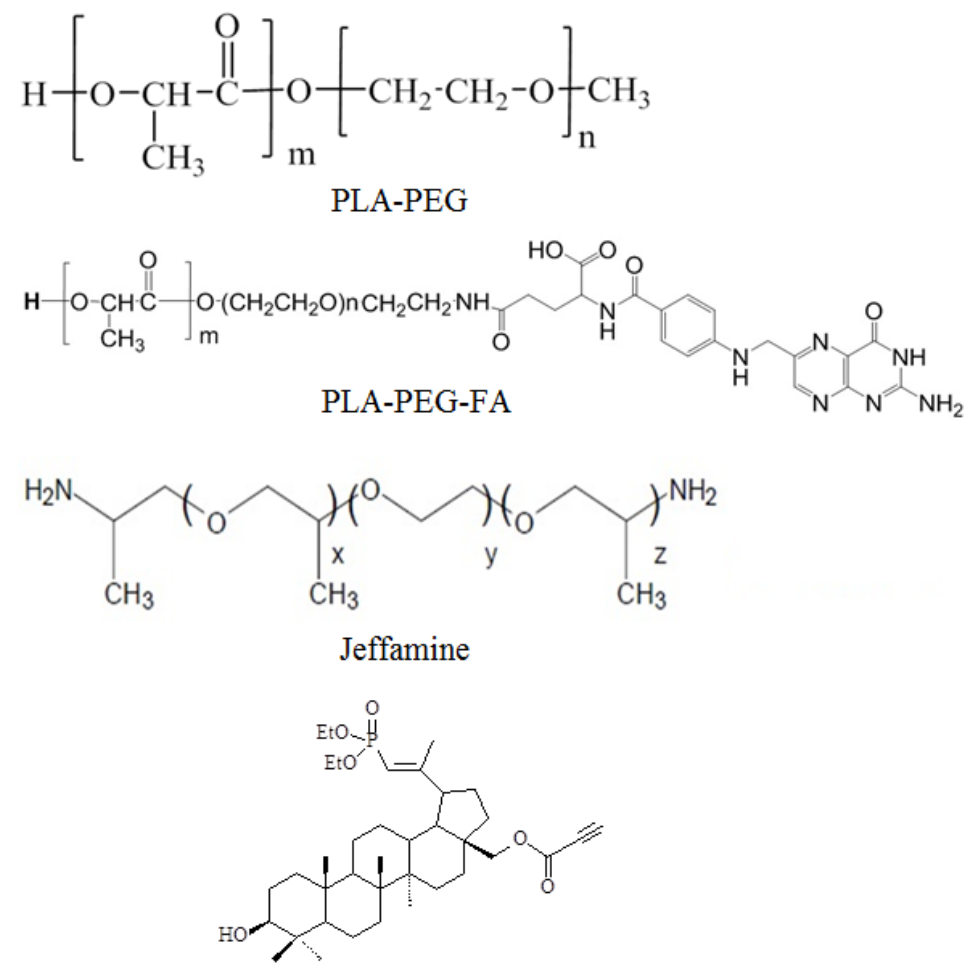

E-29-diethoxyphosphoryl-28-O-propynoylbetulin

Figure 1. Chemical structures of PLA-PEG, PLA-PEG-FA, Jeffamine and E-29diethoxyphosphoryl-28-O-propynoylbetulin $(\mathrm{Mn}=630.85 \mathrm{~g} / \mathrm{mol})$.

\section{Materials and Methods}

\subsection{Materials}

PLA-PEG-FA (Fig. 1) was purchased from Nanosoft Polymers (NC, USA). The human breast cancer SK-BR-3 cell line was obtained from ATCC (HTB-30). Fetal bovine serum (FBS) was purchased from Thermo Fisher Scientific. All other organic solvents were of analytic grade from Sigma-Aldrich and used without further purification.

\subsection{Preparation of drug-loaded micelles}

Phosphonate derivative of betulin (E-29-diethoxyphosphoryl-28-O-propynoylbetulin; ECH147B) (Fig. 1) was synthesized at the Department of Organic Chemistry, Medical University of Silesia [34]. PLA-PEG diblock copolymer was synthesized according to the procedure described before [10]. The $\mathrm{M}_{\mathrm{n}}$ of PLA block was 5000 or 3000 and $\mathrm{M}_{\mathrm{n}}$ of PEG block 
was 5000 Da. The synthesis of PLA-Jeffamine-FA (PLA-Jeff-FA) was described in our previous article [23].

Betulin derivative (E-29-diethoxyphosphoryl-28-O-propynoylbetulin) loaded micelles were prepared from a mixture of PLA-PEG and PLA-PEG-FA or PLA-Jeff-FA by using co-solvent evaporation method. PLA-PEG and PLA-Jeff-FA (2.5/1, w/w) or PLA-PEG and PLA-PEG-FA $(2.5 / 1, w / w)$ were dissolved in methylene chloride, and the solution was added to distilled water to obtain a concentration of $1 \mathrm{mg} / \mathrm{mL}$. The mixture was stirred at room temperature for $3 \mathrm{~h}$ and left for solvent evaporation for $24 \mathrm{~h}$, yielding blank micelles. For analysis of drug loading properties, micelles from PLA5000-PEG5000 were also prepared by using the method described above. Betulin derivative dissolved in ethanol was then added to the micelle solution. The initial drug loading was $15 \%$ (wt-\%). The mixture was stirred at $350 \mathrm{rpm}$ for $3 \mathrm{~h}$, followed by centrifugation at $3000 \mathrm{rpm}$ for $5 \mathrm{~min}$ to eliminate the unloaded drug. The supernatant was recovered, lyophilized and stored at $4^{\circ} \mathrm{C}$ for further analysis.

For the determination of drug loading content (LC) and the encapsulation efficiency (EE), lyophilized micelles were dissolved in ethanol at a concentration of $1 \mathrm{mg} / \mathrm{mL}$ and analyzed by HPLC. The LC was defined as the ratio of the weight of loaded drug to that of drug-loaded micelles, and the EE as the ratio of the weight of loaded drug to that of an added drug.

\subsection{Characterization of micelles}

\subsubsection{TEM analysis}

Morphology of micelles was observed with Cryogenic Transmission Electron Microscopy (cryo-TEM) using a Tecnai F20 X TWIN microscope (FEI Company, Hillsboro, Oregon, USA) equipped with field emission gun, operating at an acceleration voltage of $200 \mathrm{kV}$. Images were recorded on the Eagle 4k HS camera (FEI Company, Hillsboro, Oregon, USA) and processed with TIA software (FEI Company, Hillsboro, Oregon, USA). Specimen preparation was done by vitrification of the aqueous solutions on grids with holey carbon film (Quantifoil R 2/2; 
Quantifoil Micro Tools GmbH, Großlöbichau, Germany). Prior to use, the grids were activated for 15 seconds in oxygen plasma using a Femto plasma cleaner (Diener Electronic, Ebhausen, Germany). $3 \mu \mathrm{L}$ of micellar solution at the concentration of $10 \mathrm{mg} / \mathrm{mL}$ was applied to the grid, and then given to blotting with filter paper and rapid freezing in liquid ethane using a fully automated blotting device Vitrobot Mark IV (FEI Company, Hillsboro, Oregon, USA). After preparation, the vitrified specimens were kept under liquid nitrogen until they were inserted into a cryo-TEM-holder Gatan 626 (Gatan Inc., Pleasanton, USA) and analyzed in the TEM at $-178^{\circ} \mathrm{C}$.

\subsubsection{FTIR analysis}

Fourier transform infrared (FTIR) spectra were recorded on JASCO FT/IR-6000 spectrometer. The samples were analyzed in a form of pellets in $\mathrm{KBr}$ (folic acid and drug) and as films obtained after evaporating from solutions in $\mathrm{CHCl}_{3}$ onto $\mathrm{KBr}$ windows (polymers and polymer - drug mixtures).

\subsubsection{NMR spectroscopy}

Proton nuclear magnetic resonance $\left({ }^{1} \mathrm{H}\right.$ NMR) spectroscopy was applied for the analysis of micelles. Lyophilized micelles or free drugs were dissolved in DMSO- $\mathrm{d}_{6}$ before analysis. Spectra were recorded at Bruker-Avance II Ultrashiels Plus spectrometer (600M Hz). Chemical shifts $(\delta)$ were given in ppm using tetramethylsilane as an internal reference.

\subsection{Drug release study}

The in vitro release of drug from micelles was realized by the dialysis method. Lyophilized drug-loaded micelles were dispersed in phosphate buffered saline (PBS; pH 7.4) at a concentration of $2 \mathrm{mg} / \mathrm{mL}$ and loaded into a $1 \mathrm{~mL}$ Float-A-Lyzer G2 dialysis device (MWCO of 3,5-5 kDa; Spectra/Por). The dialysis device was placed in $40 \mathrm{~mL}$ of PBS ( $\mathrm{pH} 7.4$ ) and incubated at $37{ }^{\circ} \mathrm{C}$. The medium was changed regularly to ensure sink conditions. A $25 \mu \mathrm{L}$ of the micellar solution was collected at 1, 4, 24, 48, 96, 168 and $264 \mathrm{~h}$ and replaced by the same 
volume of fresh PBS. The samples were lyophilized and dissolved in $0.5 \mathrm{~mL}$ of EtOH before quantitative assessment of drug by means of reverse phase high-performance liquid chromatography (RP-HPLC) using a VWR/Hitachi LaChrom Elite ${ }^{\circledR}$ chromatograph equipped with a LiChrospher ${ }^{\circledR} \mathrm{RP}-18$ column $(250 \mathrm{~mm} \times 4 \mathrm{~mm}, 5 \mu \mathrm{m})$. The mobile phase was a mixture of acetonitrile and water (86/14, v/v). Measurements were performed at $25^{\circ} \mathrm{C}$ at a flow rate of $1.0 \mathrm{~mL} / \mathrm{min}$. The UV detection was set at $210 \mathrm{~nm}$.

\subsection{In vitro cytotoxicity studies}

The human breast cancer SK-BR-3 cell line was applied to study cytotoxicity of both drug loaded and drug free micelles. The cells were cultured in McCoy's 5a Medium supplemented with $10 \%$ fetal bovine serum, $100 \mathrm{U} / \mathrm{mL}$ penicillin and $100 \mu \mathrm{g} / \mathrm{mL}$ streptomycin and $10 \mathrm{mM}$ HEPES pH 7.3. The cells were cultivated at $37^{\circ} \mathrm{C}$, in a humidified atmosphere containing $5 \%$ $\mathrm{CO}_{2}$. They were passaged using $0.25 \%$ Trypsin- 0.5 mM EDTA.

\subsubsection{Sulforhodamine B (SRB) assay}

To study the cell proliferation, $200 \mu \mathrm{L}$ aliquots of cell suspension, containing $3 \times 10^{3}$ cells, were transferred to wells of the 96-well plates and cultured in standard medium for $24 \mathrm{~h}$ to ensure cell adhesion. Then, the medium was removed and replaced with a fresh one, containing free drug or drug loaded micelles. Micelles were dissolved in culture medium and filtered (through a sterile $0.2 \mu \mathrm{m}$ membrane filter) immediately before adding to the wells. The concentrations of polymers in cell culture media treated with drug loaded micelles are presented in Table 1. Free drugs were dissolved in $99.8 \%$ ethanol at concentration of $20 \mathrm{mM}$ and then added to the culture medium. The cells were incubated with tested formulations for 72 hours. At the end of the incubation period, the culture medium was removed and cells were fixed at $4{ }^{\circ} \mathrm{C}$ with $10 \%$ trichloroacetic acid, washed twice with deionized water and stained with $0.4 \%$ sulforhodamine B (dissolved in $1.0 \%$ acetic acid). The unincorporated stain was washed out using $1.0 \%$ acetic acid solution, the incorporated stain was liberated by means of $200 \mu \mathrm{L}$ of $10 \mathrm{mM}$ 
tris(hydroxymethyl)aminomethane solution. Absorbance was read at $570 \mathrm{~nm}$ and $690 \mathrm{~nm}$ (reference wavelength) using the Infinite 200 Pro plate reader (Tecan).

Table 1. Concentration of polymers in cell culture media treated with drug loaded micells.

\begin{tabular}{llll}
\hline \multicolumn{1}{c}{ Drug concentration } & $\mathbf{3}(\boldsymbol{\mu M})$ & $\mathbf{1 0}(\boldsymbol{\mu M})$ & $\mathbf{3 0}(\boldsymbol{\mu M})$ \\
Polymer forming micelle & & & \\
\hline PLA $_{\mathbf{5 0 0}}$ PEG $_{\mathbf{5 0 0 0}}+$ PLA-Jeff-FA & $377.4 \mu \mathrm{g} / \mathrm{mL}$ & $125.8 \mu \mathrm{g} / \mathrm{mL}$ & $37.7 \mu \mathrm{g} / \mathrm{mL}$ \\
PLA $_{\mathbf{5 0 0}}$ PEG $_{\mathbf{5 0 0 0}}+$ PLA-PEG-FA & $994.3 \mu \mathrm{g} / \mathrm{mL}$ & $331.4 \mu \mathrm{g} / \mathrm{mL}$ & $99.4 \mu \mathrm{g} / \mathrm{mL}$ \\
PLA $_{\mathbf{3 0 0 0}}$ PEG $_{\mathbf{5 0 0}}+$ PLA-Jeff-FA & $144.3 \mu \mathrm{g} / \mathrm{mL}$ & $48.1 \mu \mathrm{g} / \mathrm{mL}$ & $14.4 \mu \mathrm{g} / \mathrm{mL}$ \\
& & & \\
\hline
\end{tabular}

\subsubsection{Cell apoptosis assay}

Internucleosomal fragmentation of genomic DNA was assessed using the Cell Death Detection ELISA $^{\text {PLUS }}$ kit (Roche) in order to estimate apoptosis induction. In this technique, mono- and oligonucleosomes are detected in the cytoplasmic cell fraction using specific antibodies. Cells were seeded in 96 -well plates at a density of $5 \times 10^{3}$ cells per well and cultured for $24 \mathrm{~h}$. Then, cells were treated with tested formulations for 24 hours. After treatment, plates were centrifuged (200 g; 10 min.), media were removed and $200 \mu \mathrm{L}$ of lysis buffer was added to the wells for 30 min. Then, plates were centrifuged again and $20 \mu \mathrm{L}$ of supernatant (cytoplasmic fraction) was transferred to the streptavidin-coated 96-well plate. Enrichment of the cytoplasmic fraction with DNA fragments, released from a cell nucleus, was determined using the sandwich ELISA assay and enrichment factor $(\mathrm{EF})$ was calculated according to the formula: $\mathrm{EF}=\mathrm{A}_{\mathrm{S}} / \mathrm{A}_{\mathrm{C}}$; where $\mathrm{A}_{\mathrm{S}}$ absorbance of the sample; $A_{C}-$ absorbance of control.

\section{Results}

\subsection{Characterization of FA-targeted micelles}

Three kinds of micelles for targeted cancer therapy were obtained from mixture of PLA5000PEG $_{5000}$ and PLA-Jeff-FA (1), PLA $3000-$ PEG $_{5000}$ and PLA-Jeff-FA (2), PLA5000-PEG 5000 and 
PLA-PEG-FA (3). The characteristics of the copolymers used to form micelles are presented in Table 2. Micelles with PLA-Jeff-FA were obtained from a combination of polymer with longer PLA block (PLA5000-PEG 5000$)$, in which molar mass of PLA and PEG was equal $\left(\mathrm{M}_{\mathrm{n}}=5000\right.$ Da) or with copolymer with shorter PLA block of 3000 Da (PLA $\left.3000-P_{56} G_{500}\right)$. These kinds of polymers were selected to analyze the influence of hydrophobic block length of PLA-PEG on micelles' properties. For comparison of the effect of the polymer with functional moiety, PLA5000-PEG5000 was mixed either with PLA-Jeff-FA or PLA-PEG-FA.

Table 2. Characteristics of copolymers $\left(\mathrm{M}_{\mathrm{n}}=\right.$ numer-average molar mass; $\mathrm{DP} \mathrm{PEG}_{\mathrm{P}}=$ degree of polymerization of PEG ( $\left.\mathrm{M}_{\mathrm{nPEG}} / 44\right)$; DPPLA); DPPLA = degree of polymerization of PLA $\left(\mathrm{M}_{\mathrm{nPLA}} / 72\right)$.

\begin{tabular}{llllll}
\hline Copolymer & MnPEg & DPPeg & MnPLA & DPPLA & MnJeff \\
\hline PLA3000-PEG5000 & 5000 & 114 & 3000 & 42 & - \\
PLA5000-PEG5000 & 5000 & 114 & 5000 & 69 & - \\
PLA-Jeff-FA & - & - & 1200 & 17 & 1900 \\
PLA-PEG-FA & 5000 & 114 & 5000 & 69 & - \\
\hline
\end{tabular}

The morphology of micelles was observed using cryo-TEM. As shown in Fig. 2, the mixture of PLA $_{5000}$ PEG $_{5000}$ and PLA-Jeff-FA (Fig. 2A) or PLA ${ }_{5000}$ PEG $_{5000}$ and PLA-PEG-FA (Fig. 2B) formed exclusively filomicelles of $100-400 \mathrm{~nm}$ length. The co-existence of filomicelles of $\approx$ $100 \mathrm{~nm}$ length and spherical micelles of $10 \mathrm{~nm}$ diameter was observed for the mixture of PLA $_{3000}$ PEG $_{5000}$ and PLA-Jeff-FA (Fig. 3A). Importantly, the morphology of all kinds of 
micelles did not change after drug loading as shown for $\mathrm{PLA}_{3000} \mathrm{PEG}_{5000}$ and PLA-Jeff-FA (Fig. 3B).
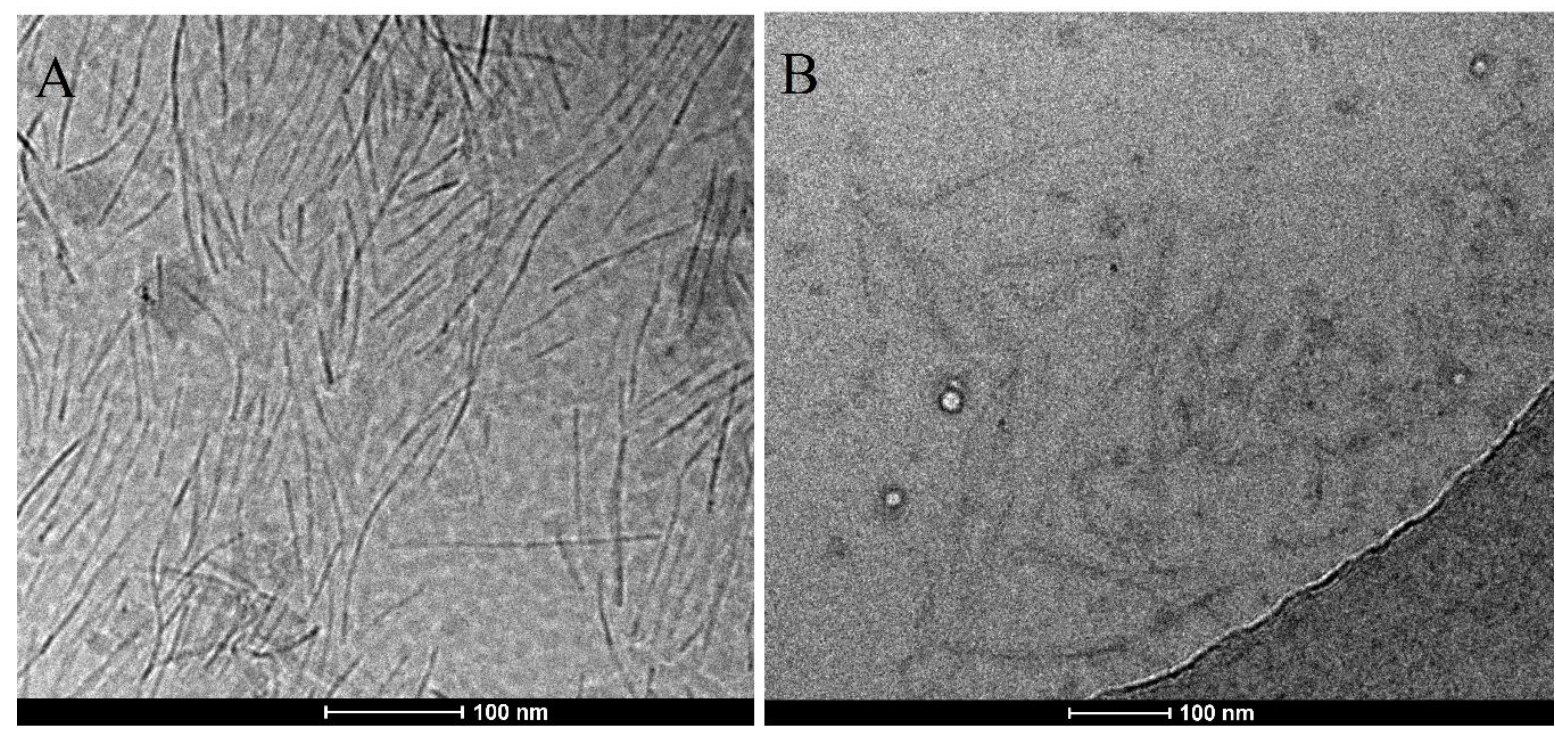

Figure 2. Cryo-TEM image of micelles obtained from mixture of PLA ${ }_{5000} \mathrm{PEG}_{5000}$ and PLAJeff-FA (A), or mixture of PLA ${ }_{5000} \mathrm{PEG}_{5000}$ and PLA-PEG-FA (B).
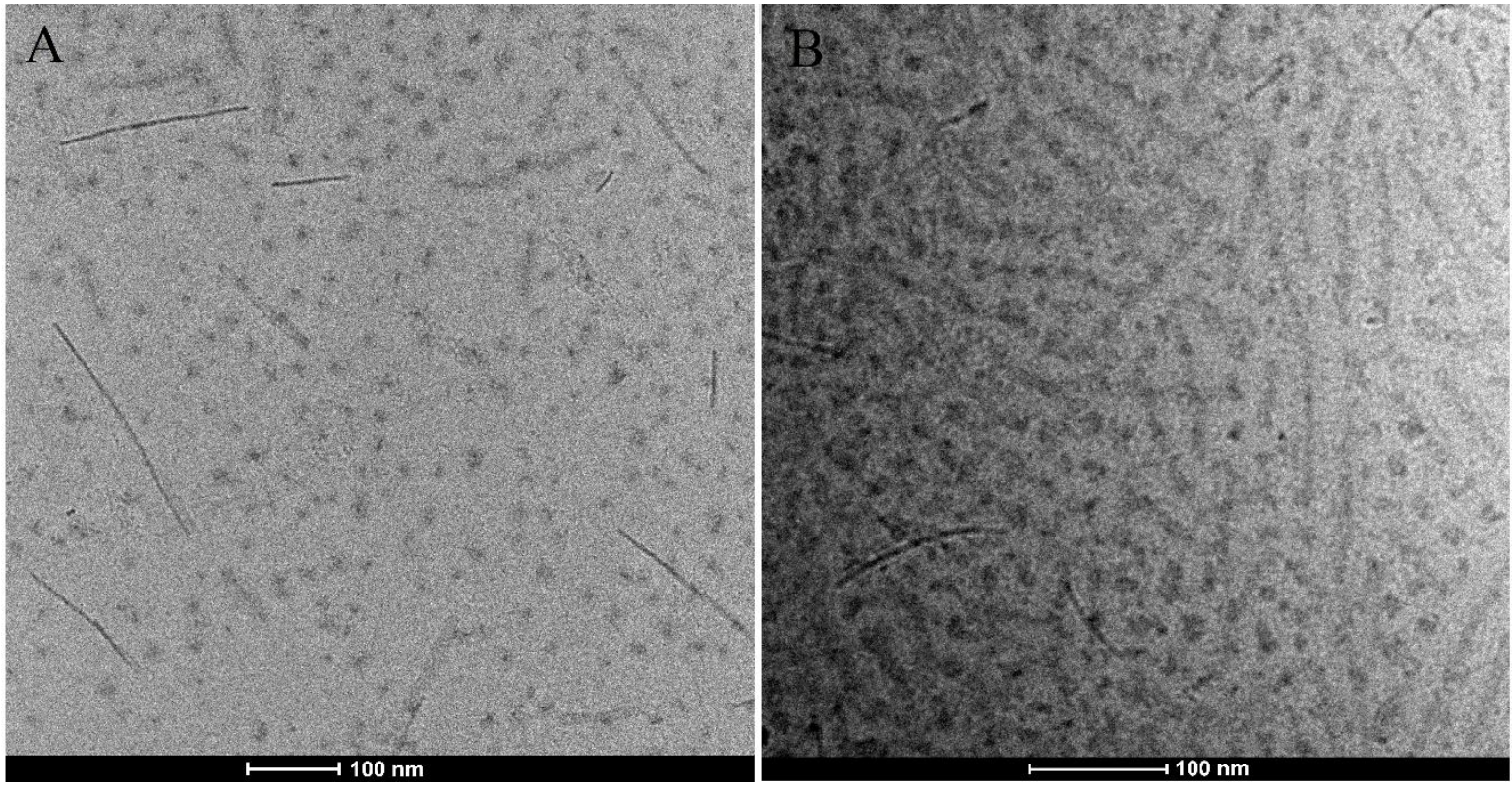

Figure 3. Cryo-TEM image of micelles obtained from mixture of PLA $_{3000}$ PEG $_{5000}$ and PLAJeff-FA: drug-free (A) and drug-loaded (B). 
A novel anticancer agent derived from natural plants, E-29-diethoxyphosphoryl-28-Opropynoylbetulin, was encapsulated into micelles. The lyophilized micelles formed translucent solution after re-dispersion in water, which confirmed successive drug solubilisation. The presence of drug in micelles was confirmed by means of ${ }^{1} \mathrm{H}$ NMR (Fig. 4) and HPLC (Table 3). Figure 4 presents comparatively the NMR spectra obtained in DMSO- $\mathrm{d}_{6}$ for a free drug (E29-diethoxyphosphoryl-28-O-propynoylbetulin), drug free micelles and drug loaded micelles. Signals arising from methine $(5.3 \mathrm{ppm})$ and methyl $(1.6 \mathrm{ppm})$ protons of PLA and methylene (3.6 ppm) protons of PEG are observed in all spectra obtained for drug free and drug-loaded micelles. Moreover, the signals of E-29-diethoxyphosphoryl-28-O-propynoylbetulin are visible in the spectra of all drug-loaded micelles. Methyl groups of betulin derivative are identified at $0.5-1.0 \mathrm{ppm}$.

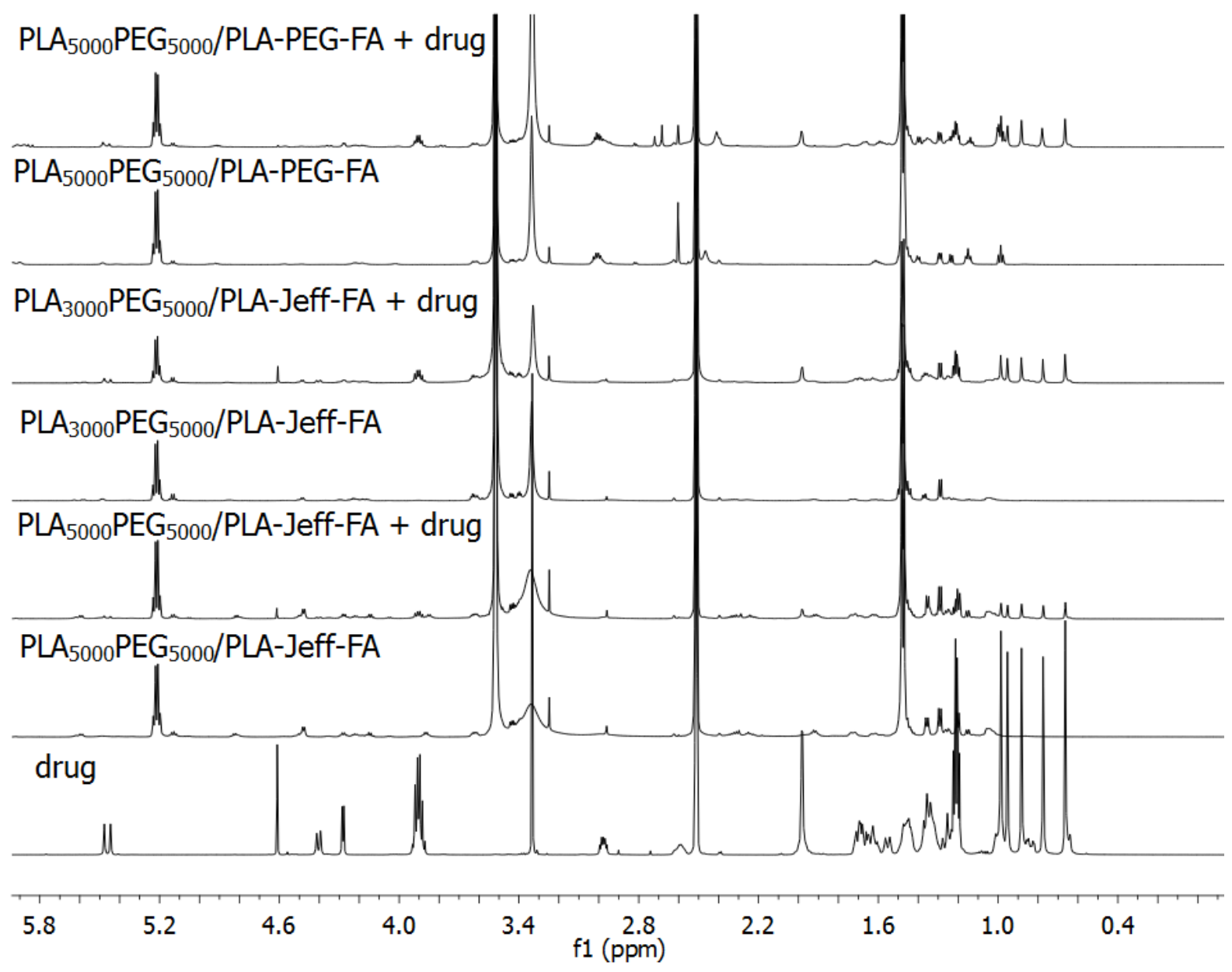


Figure 4. ${ }^{1} \mathrm{H}$ NMR spectra in DMSO- $\mathrm{d}_{6}$ of free drug, drug-free micelles, and drug-loaded micelles.

Table 3 presents the drug loading properties of the various systems. PLA ${ }_{5000} \mathrm{PEG}_{5000}$ micelles were used for comparison with micelles obtained from mixture of two kinds of polymers. Micelles obtained from PLA ${ }_{5000} \mathrm{PEG}_{5000}$ or mixture of PLA $\mathrm{P}_{500} \mathrm{PEG}_{5000}$ and PLA-Jeff-FA characterized comparable encapsulation efficiency $(\approx 34 \%)$ and loading content $(\approx 5 \%)$. Significantly lower amount of E-29-diethoxyphosphoryl-28-O-propynoylbetulin was encapsulated into PLA ${ }_{5000} \mathrm{PEG}_{5000}+$ PLA-PEG-FA micelles $(1.9 \%)$, in which EE was below $13 \%$. The highest drug loading was obtained for PLA ${ }_{3000} \mathrm{PEG}_{5000}+$ PLA-Jeff-FA with EE of $87 \%$.

Table 3. Encapsulation efficiency and loading content data of E-29-diethoxyphosphoryl-28-Opropynoylbetulin in PLA-PEG micelles (Data represent mean value \pm S.D., $n=3$ ).

\begin{tabular}{lccc}
\hline Polymer forming micelle & $\begin{array}{c}\text { Initial drug } \\
\text { loading (wt-\%) }\end{array}$ & LC (\%) & EE (\%) \\
& 15 & $5.1 \pm 0.03$ & $34.2 \pm 0.24$ \\
\hline PLA5000PEG5000 & 15 & $5.0 \pm 0.26$ & $33.7 \pm 1.74$ \\
PLA5000PEG5000 + PLA-Jeff-FA & 15 & $1.9 \pm 0.03$ & $12.9 \pm 0.23$ \\
PLA5000PEG5000 + PLA-PEG-FA & & & \\
PLA3000PEG5000 + PLA-Jeff-FA & 15 & $13.1 \pm 0.09$ & $87.2 \pm 0.59$ \\
\hline
\end{tabular}

\subsection{In vitro release}

The in vitro release of E-29-diethoxyphosphoryl-28-O-propynoylbetulin from micellar systems was studied by means of the dialysis method. Figure 5 presents the release profiles from 
different FA-targeted PLA-PEG micelles. In the group of micelles obtained from PLA-PEG and PLA-Jeff-FA, faster release was observed for copolymer with the shorter PLA chain (PLA ${ }_{3000} \mathrm{PEG}_{5000}+\mathrm{PLA}-\mathrm{Jeff}-\mathrm{FA}$ ) compared to PLA5000 $\mathrm{PEG}_{5000}+\mathrm{PLA}-\mathrm{Jeff}-\mathrm{FA}$ filomicelles. The differences were significant especially in the initial phase. $26.0 \%$ of the drug was released after $1 \mathrm{~h}$ from PLA $_{3000} \mathrm{PEG}_{5000}+$ PLA-Jeff-FA micelles and only $2.7 \%$ from PLA ${ }_{5000} \mathrm{PEG}_{5000}+\mathrm{PLA}-$ Jeff-FA. Beyond $96 \mathrm{~h}$ the rate of drug release was comparable for these two kinds of micelles. Significantly slower release was observed for PLA ${ }_{5000} \mathrm{PEG}_{5000}+\mathrm{PLA}-\mathrm{PEG}-\mathrm{FA}$ micelles. $1.7 \%$, $20 \%$ and $33 \%$ of betulin derivative was released from this kind of micelles after 1, 24 and 48 h, respectively.

In all kinds of micelles drug release was almost completed after $264 \mathrm{~h}-98.9 \%$ of the drug was released from PLA ${ }_{3000} \mathrm{PEG}_{5000}+\mathrm{PLA}-\mathrm{Jeff}-\mathrm{FA}, 94.4 \%$ from PLA ${ }_{5000} \mathrm{PEG}_{5000}+\mathrm{PLA}-\mathrm{Jeff}-\mathrm{FA}$ and

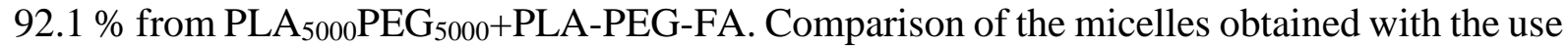
of PLA-Jeff-FA or PLA-PEG-FA showed the slowest release of betuline derivative from PLA $_{5000}$ PEG $_{5000}+$ PLA-PEG-FA micelles.

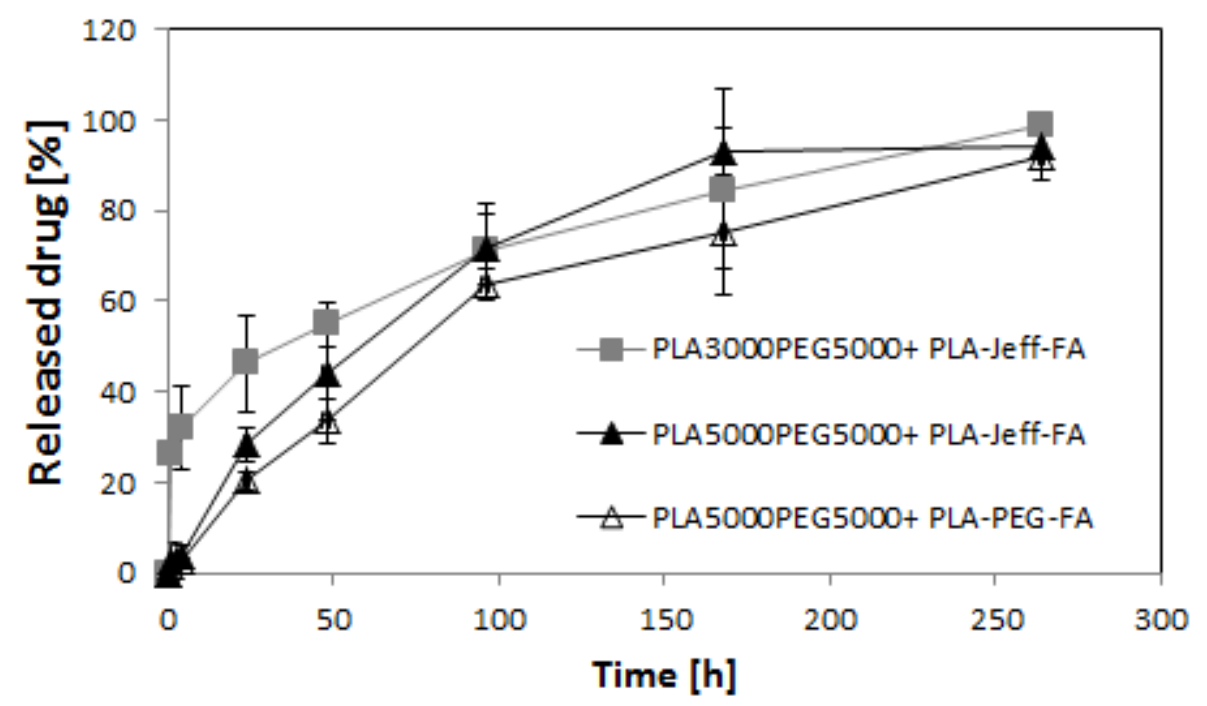

Figure 5. In vitro release of E-29-diethoxyphosphoryl-28-O-propynoylbetulin from FAtargeted PLA-PEG micelles (S.D. shown as error bars, $n=3$ ). 


\subsection{Analysis of drug-polymer interactions}

FTIR spectroscopy was used to evaluate possible interactions between the polymer and betulin derivative as shown in Fig. 6. In the spectra of lyophilized drug loaded micelles, the bands characteristic of drugs are barely visible due to the low drug content. Therefore, FTIR spectra were recorded for 1:1 weight ratio mixtures of polymer and drug. The FTIR spectra of folic acid (FA), drug (E-29-diethoxyphosphoryl-28-O-propynoylbetulin), polymer (PLA-PEG-FA and PLA-Jeff-FA) and mixture drug and polymer were recorded (Fig. 6-8).

FTIR spectra of a mixture of E-29-diethoxyphosphoryl-28-O-propynoylbetulin and PLA-JeffFA showed that all the bands originating from polymer and drug were the arithmetic sum of spectra of the particular components (Fig. 6 A-B).
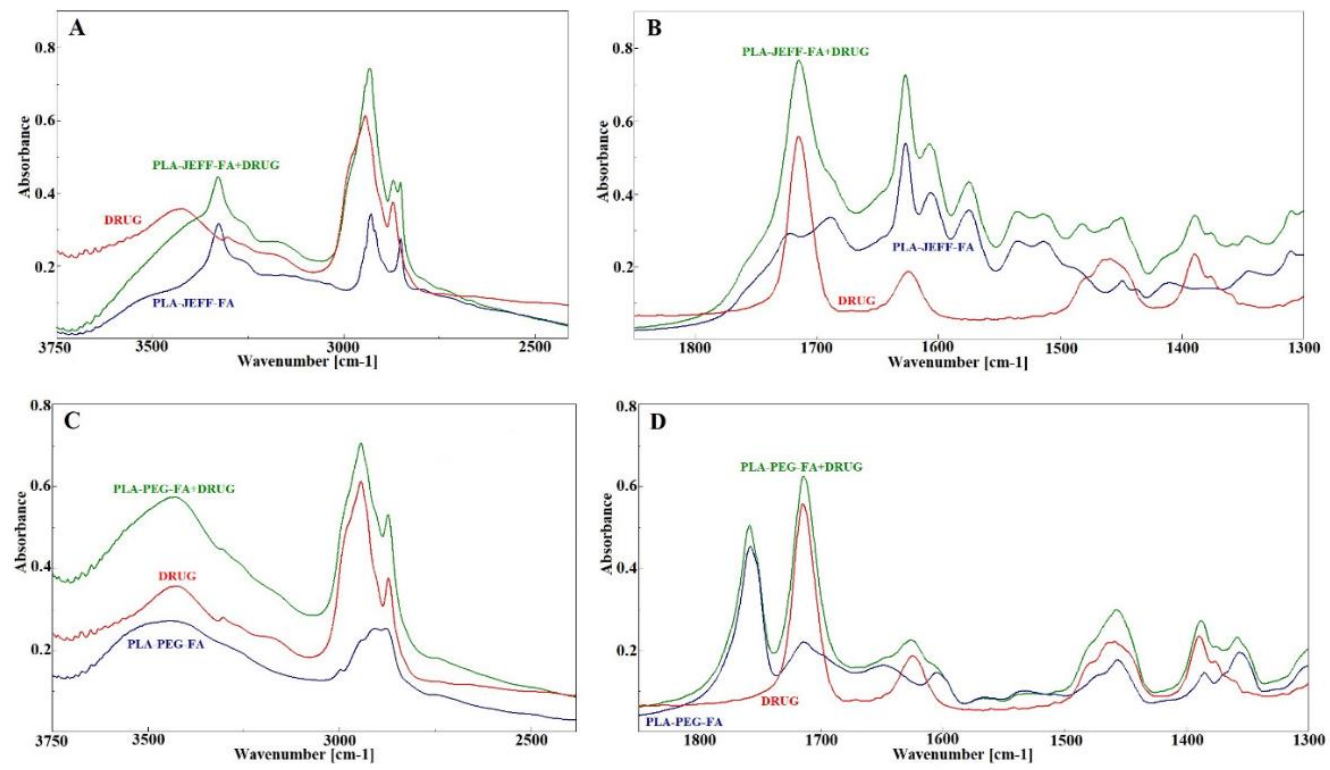

Figure 6. FTIR spectra of drug, PLA-Jeff-FA and PLA-Jeff-FA+drug (A and B) and drug, PLAPEG-FA and PLA-PEG-FA+drug (C and D).

However, some changes were observed in the case of a mixture of drug and PLA-PEG-FA (Fig. 6 C-D), especially in the shape of the band assigned to $\mathrm{C}=\mathrm{O}$ ester groups of PLA (Fig. 6D). Figure 7 presents comparatively the spectrum recorded for PLA-PEG-FA+drug with that of the arithmetic sum of the components. The band at $1758 \mathrm{~cm}^{-1}$ showed lower intensity in the original 
spectrum than in the sum of spectra. Moreover, a shoulder corresponding to vibrations of bonded $\mathrm{C}=\mathrm{O}$ ester groups at about $1750 \mathrm{~cm}^{-1}$ showed higher intensity. This may suggest that the addition of drug to PLA-PEG-FA causes formation of more bonded $\mathrm{C}=\mathrm{O}$ groups due to their interaction with $\mathrm{OH}$ groups of E-29 -diethoxyphosphoryl-28-O-propynoylbetulin. The interactions with $\mathrm{OH}, \mathrm{NH}$ or $\mathrm{NH}_{2}$ groups of FA should be excluded because the band characteristic for vibrations of $\mathrm{C}=\mathrm{O}$ acid and bands of the amide I and II from FA remained unchanged. A detailed analysis was conducted to explain this phenomenon. The FTIR spectrum of FA was analysed in comparison with those of PLA-PEG-FA and PLA-Jeff-FA (Fig. 8). Table 4 presents assignment of the most characteristic bands of the studied compounds.
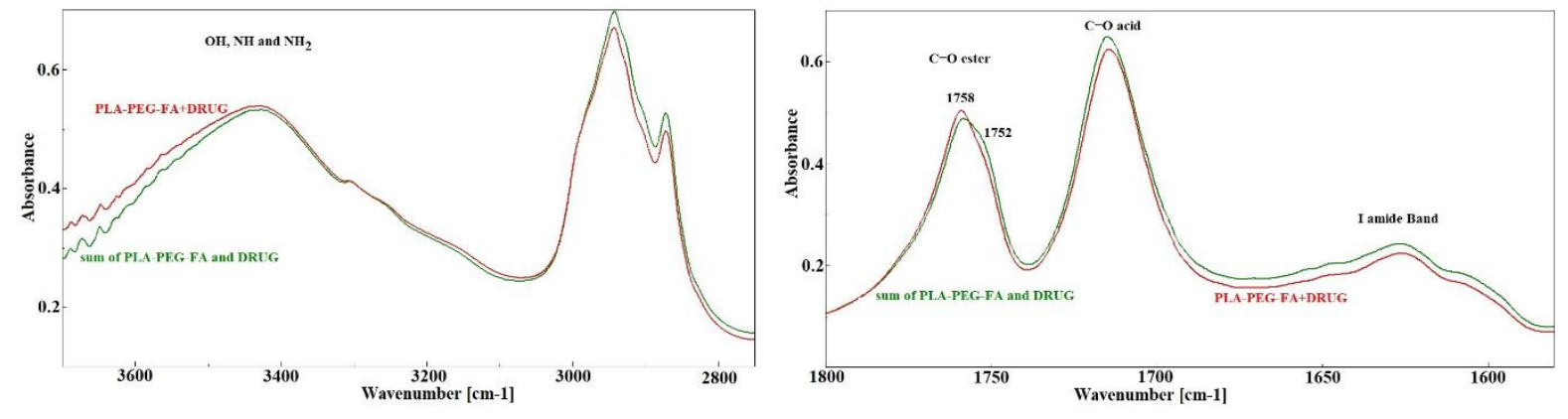

Figure 7. Comparison of FTIR spectrum of PLA-PEG-FA+drug and spectra of arithmetic sum of PLA-PEG-FA and drug.

Table 4. Assignment of the most characteristic bands in FTIR spectra of PLA-PEG-FA, PLAJeff-FA, FA and drug ( $v$ - stretching vibrations, sh - shoulder, unsat - unsaturated, $\mathrm{Ph}$ - phenyl, Py - pyrene).

\begin{tabular}{lllll}
\hline PLA-PEG-FA & PLA-Jeff-FA & FA & Drug & Assignment \\
\hline $3500 \mathrm{sh}$ & $3500 \mathrm{sh}$ & 3544 & & $v \mathrm{OH}$ \\
3443 & & 3412 & & \\
& & & 3425 & \\
3275 & 3326 & 3323 & $3302 \mathrm{sh}$ & $v \mathrm{NH}_{2}$ and \\
\hline & $3264 \mathrm{sh}$ & 3117 & & $\mathrm{NH}$ \\
\hline 1758 & & & 2113 & $v \mathrm{C} \equiv \mathrm{C}$ \\
$1750 \mathrm{sh}$ & $1750 \mathrm{sh}$ & & & $v \mathrm{C}=\mathrm{O}$ ester \\
\hline
\end{tabular}




\begin{tabular}{|c|c|c|c|c|}
\hline $\begin{array}{l}1715 \\
1700\end{array}$ & $\begin{array}{l}1722 \\
1688\end{array}$ & 1696 & & $\begin{array}{l}\nu \mathrm{C}=\mathrm{O} \text { acid } \\
\text { FA free } \\
\text { bonded }\end{array}$ \\
\hline & & & $\begin{array}{l}1715 \\
1625\end{array}$ & $\begin{array}{l}v \mathrm{C}=\mathrm{O} \text { ester } \\
\text { unsat free } \\
\text { bonded }\end{array}$ \\
\hline 1648 & 1626 & 1639 & & $\begin{array}{l}\text { I amide } \\
\text { bands FA }\end{array}$ \\
\hline $\begin{array}{l}1605 \\
1565 \\
1508\end{array}$ & $\begin{array}{l}1606 \\
1574 \\
1513\end{array}$ & $\begin{array}{l}1605 \\
1570 \\
1515 \\
1485 \\
\end{array}$ & & $\begin{array}{l}v \mathrm{Ph} \text { and } \mathrm{Py} \\
\text { and } \delta \mathrm{NH} \\
\text { amine FA }\end{array}$ \\
\hline 1532 & 1534 & 1542 & & $\begin{array}{l}\text { II amide } \\
\text { bands FA }\end{array}$ \\
\hline 1131 & 1127 & & & $v \mathrm{C}-\mathrm{O}-\mathrm{C}$ \\
\hline \multirow[t]{2}{*}{1096} & 1088 & & & PEG/JEFF \\
\hline & & & 1227 & $v \mathrm{P}=\mathrm{O}$ \\
\hline
\end{tabular}

There are some relatively sharp bands in the spectrum of FA corresponding to the stretching vibrations of $\mathrm{OH}, \mathrm{NH}$ and $\mathrm{NH}_{2}$ groups (free and bonded) (Fig. 8A). The band corresponding to the $\mathrm{C}=\mathrm{O}$ acid stretching vibrations was detected at $1696 \mathrm{~cm}^{-1}$ (Fig. 8B), which is typical for bonded ones. Also, the amide I bands are mainly represented by stretching vibrations of $\mathrm{C}=\mathrm{O}$ amide groups $\left(1639 \mathrm{~cm}^{-1}\right)$, and the amide II band - mainly due to deformation vibrations of $\mathrm{NH}$ and $\mathrm{NH}_{2}$ groups $\left(1542 \mathrm{~cm}^{-1}\right)$ appeared in the positions indicating that they were bonded. This confirmed the presence of hydrogen bond type interactions in FA compound. Comparison of the spectra of polymers (PLA-PEG-FA and PLA-Jeff-FA) and FA shows that the bands assigned to FA changed positions and shapes, suggesting changes in hydrogen bond distributions. This fact was observed especially for PLA-PEG-FA, because in the region of $\mathrm{OH}$, $\mathrm{NH}$ and $\mathrm{NH}_{2}$ stretching vibrations only one broad band with a maximum at $3443 \mathrm{~cm}^{-1}$ and a shoulder at about $3500 \mathrm{~cm}^{-1}$ were detected (Fig. 8A). This may suggest that in PLA-PEG-FA hydroxyl and amide/amine groups from FA were engaged in interactions with other components. Interactions with $\mathrm{C}=\mathrm{O}$ ester group from PLA confirmed the shoulder attributed to bonded $\mathrm{C}=\mathrm{O}$ groups appearing at $1750 \mathrm{~cm}^{-1}$. Strong decrease of intensity of the bands due to 
vibrations of $\mathrm{C}=\mathrm{O}$ acid bonded groups in $\mathrm{FA}$ at $1698 \mathrm{~cm}^{-1}$ and the presence of the band at 1715 $\mathrm{cm}^{-1}$ corresponding to free $\mathrm{C}=\mathrm{O}$ acid group vibrations confirmed formation of hydrogen bonds between $\mathrm{OH}$ acid groups from $\mathrm{FA}$ and $\mathrm{C}=\mathrm{O}$ ester groups from PLA. The shift of the I amide band to higher wavenumbers $\left(1648 \mathrm{~cm}^{-1}\right)$ and the II one to lower wavenumbers $\left(1532 \mathrm{~cm}^{-1}\right)$ proved that hydrogen bonds in amide groups were weakened.
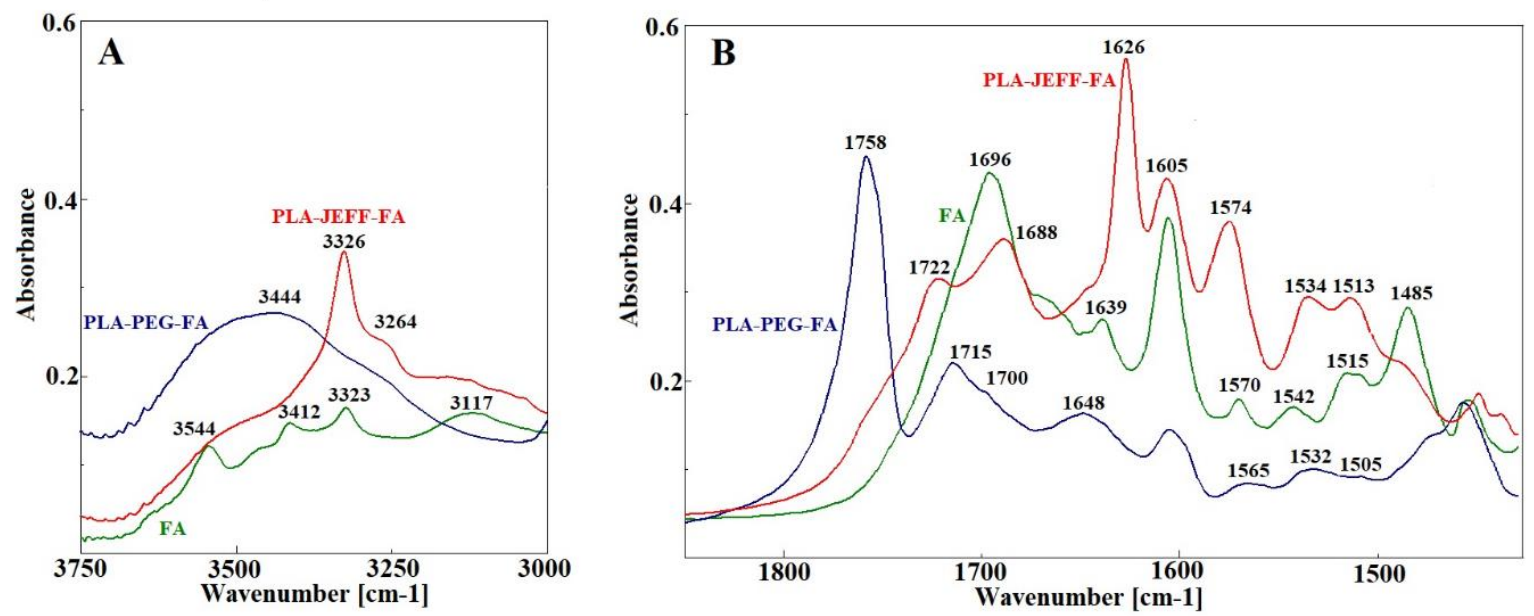

Figure 8. Comparison of FTIR spectra of polymers and FA.

In the case of PLA-Jeff-FA, the band at $3326 \mathrm{~cm}^{-1}$ attributed to $\mathrm{NH}$ and $\mathrm{NH}_{2}$ group vibrations was observed at the same position as for free FA, proving that these bands did not interact with PLA. As shown in Fig. 8B, the band characteristic for stretching vibration of bonded $\mathrm{C}=\mathrm{O}$ groups was detected as a shoulder at $1750 \mathrm{~cm}^{-1}$, indicating that all $\mathrm{C}=\mathrm{O}$ ester groups were engaged in forming hydrogen bonds. It may also indicate the lower PLA content in this mixture in comparison with PLA-PEG-FA. In fact, the PLA chain in PLA-PEG-FA was significantly longer than in PLA-Jeff-FA (Table 2). Similarly as for PLA-PEG-FA, a band originating from vibrations of free $\mathrm{C}=\mathrm{O}$ acid groups was detected at $1722 \mathrm{~cm}^{-1}$, however the band at $1688 \mathrm{~cm}^{-1}$ due to bonded $\mathrm{C}=\mathrm{O}$ acid groups was relatively strong. This indicated that less acid $\mathrm{OH}$ groups of FA interact with $\mathrm{C}=\mathrm{O}$ ester group from PLA in comparison with PLA-PEG-FA. Also, in 
contrast to PLA-PEG-FA, the amide I groups shifted to lower wavenumber $\left(1626 \mathrm{~cm}^{-1}\right)$, indicating formation of stronger hydrogen bonds than in FA, probably with $\mathrm{OH}$ acid groups. Thus, it was demonstrated that in PLA-PEG-FA interactions occurred between $\mathrm{C}=\mathrm{O}$ ester groups from PLA and $\mathrm{OH}, \mathrm{NH}$ and $\mathrm{NH}_{2}$ groups from FA, while in PLA-Jeff-FA, due to lower content of PLA, all $\mathrm{C}=\mathrm{O}$ ester groups interacted with $\mathrm{OH}$ acid groups. The lack of free $\mathrm{C}=\mathrm{O}$ ester groups in PLA-Jeff-FA caused that the $\mathrm{OH}$ groups of the drug had no possibility to interact with them. In the case of both kinds of polymers, FA and drug did not interact with each other, probably due to the spatial hindrance.

\subsection{Cytotoxicity study}

The effect of E-29-diethoxyphosphoryl-28-O-propynoylbetulin and E-29-diethoxyphosphoryl28-O-propynoylbetulin-loaded micelles on the growth of SK-BR-3 cells was determined by means of sulforhodamine B assay. As shown in Fig. 9, significant inhibition of cell proliferation was observed in the whole range of concentrations $(3-30 \mu \mathrm{M})$ in the case of free drug.

Fig. 9 shows also the effect of E-29-diethoxyphosphoryl-28-O-propynoylbetulin encapsulated in micelles on the proliferation of SK-BR-3 cells. The number of cells was not affected by the lowest drug concentration $(3 \mu \mathrm{M})$ in all micelles. Betulin derivative in PLA5000 $\mathrm{PEG}_{5000}+\mathrm{PLA}-$ Jeff-FA micelles caused a decrease of cell growth at the concentration of $10-30 \mu \mathrm{M}$. The drug released from PLA $_{3000}$PEG $_{5000}+$ PLA-Jeff-FA and PLA5000 $P_{5 G} E_{500}+$ PLA-PEG-FA micelles caused a decrease of cell growth at the highest concentration $(30 \mu \mathrm{M})$. The effect of betulin derivative - loaded micelles may be correlated with the drug release rate, because the micelles that present the slowest drug release $\left(\mathrm{PLA}_{5000} \mathrm{PEG}_{5000}+\right.$ PLA-PEG-FA) have also the lowest impact on the cell growth. 


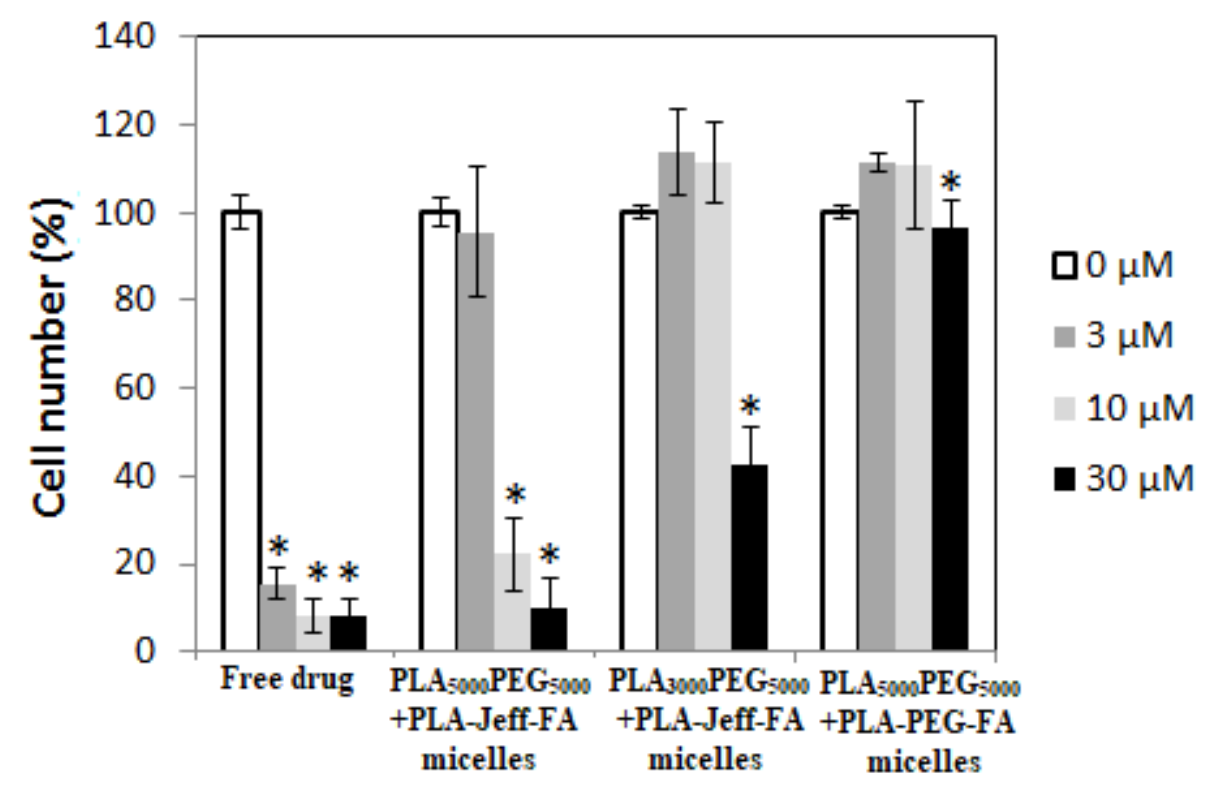

Figure 9. Effect of free drug (E-29-diethoxyphosphoryl-28-O-propynoylbetulin) and E-29diethoxyphosphoryl-28-O-propynoylbetulin - loaded micelles on proliferation of SK-BR-3 cells $( \pm \mathrm{SD} ; * \mathrm{P}<0.05)$.

The effect of drug-free micelles on cells viability was analyzed for the sake of comparison. The blank filomicelles were studied at concentrations corresponding to those of drug loaded micelles. As shown in Fig. 10, the micelles did not affect cell proliferation even at the highest concentration. This finding confirms the biocompatibility of the developed micelles, which can be used as drug carriers. 


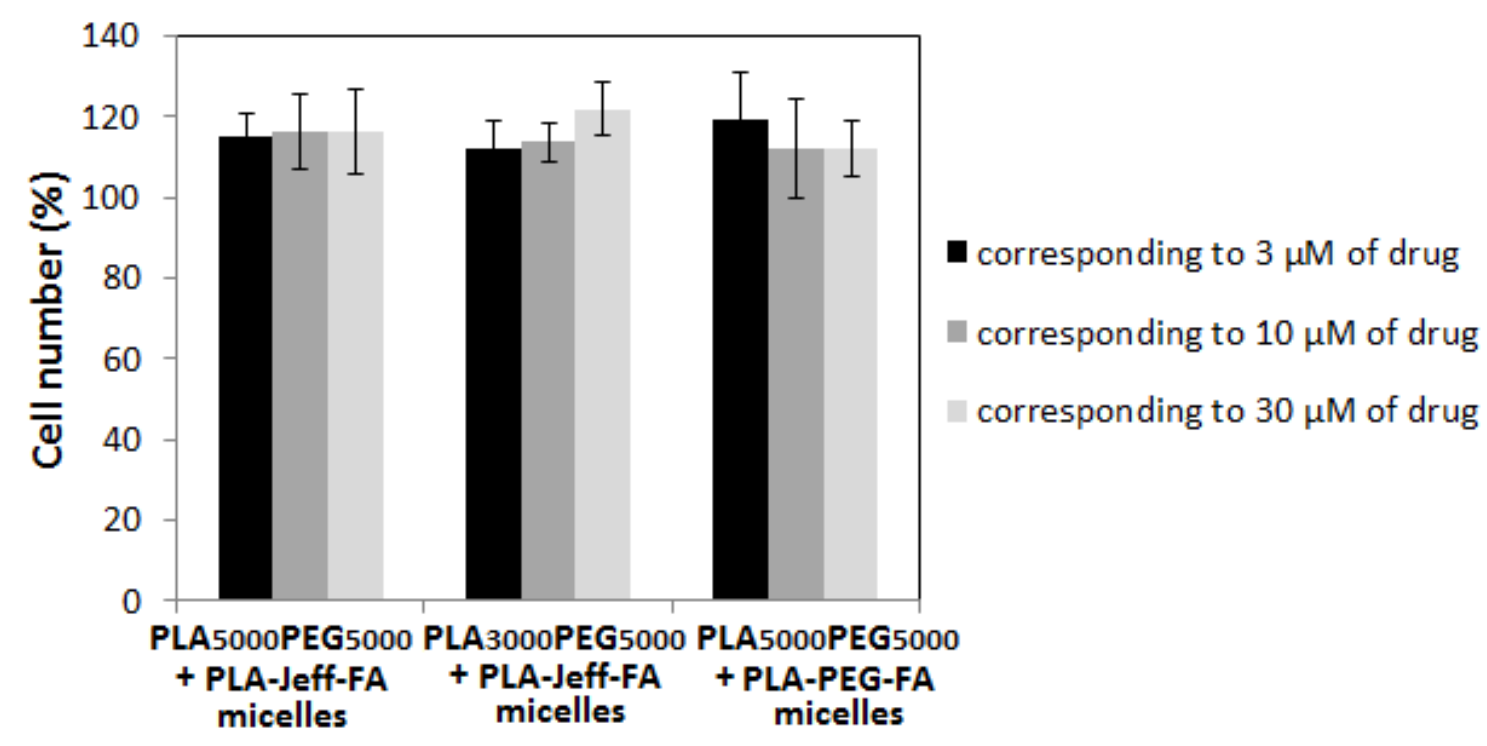

Figure 10. Effect of drug - free micelles on the proliferation of SK-BR-3 cells $( \pm \mathrm{SD}, P<0.05$ versus the control group).

The fragmentation of genomic DNA was analyzed for evaluation of the mechanism of cell death (Fig. 11). Both free drug and drug loaded PLA5000 PEG $_{5000}+$ PLA-Jeff-FA micelles induced significant DNA fragmentation. The largest amounts of DNA fragments were detected in the cytoplasmic fraction of cells treated with the drug at concentrations of $10 \mu \mathrm{M}$. In the case of drug loaded PLA $_{3000}$ PEG $_{5000}+$ PLA-Jeff-FA, significant DNA fragmentation was observed at the highest drug concentration. The effect of drug loaded PLA5000 $\mathrm{PEG}_{5000}+$ PLA-PEG-FA on SK-BR-3 cells was comparable to the untreated cells. 


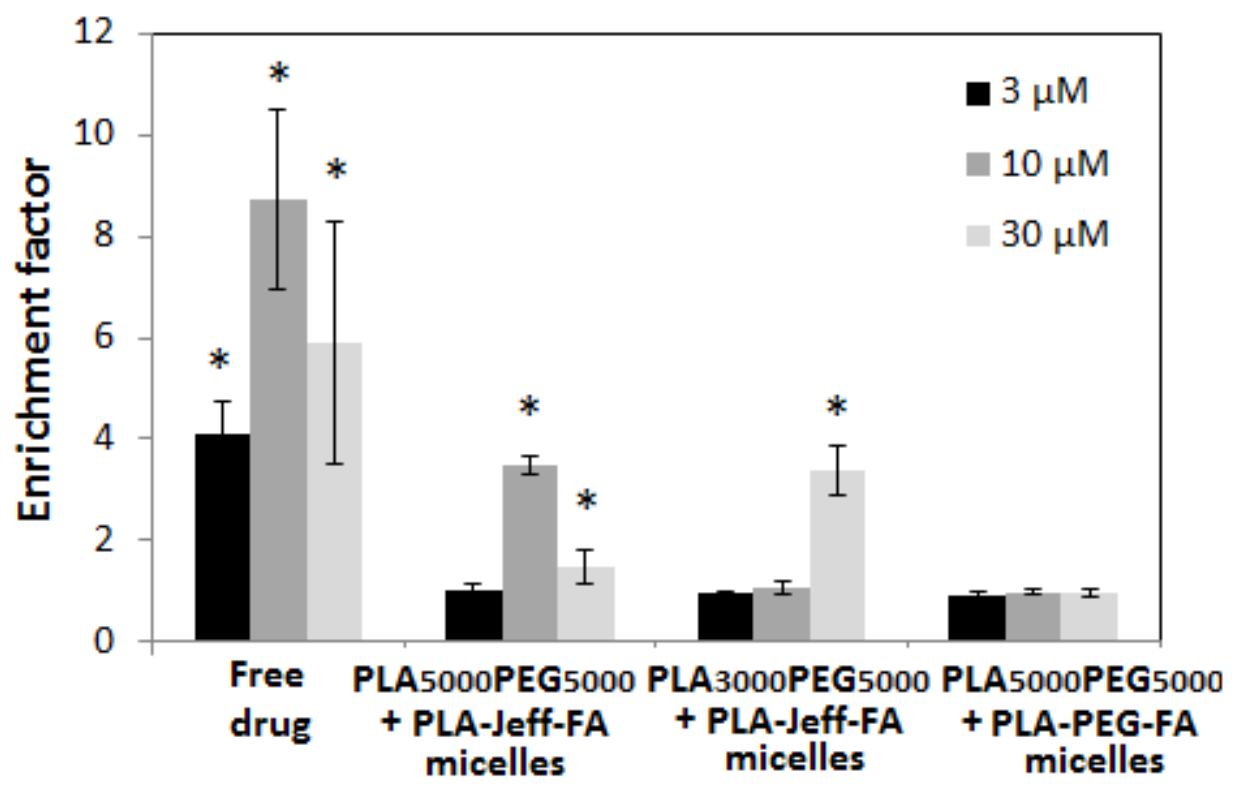

Figure 11. Determination of DNA fragmentation in SK-BR-3 cells $( \pm \mathrm{SD} ; * \mathrm{P}<0.05)$.

\section{Discussion}

Cancer is one of the major causes of death worldwide and its treatment remains very challenging. First-line therapy of solid tumors is based on surgery, radiotherapy and / or chemotherapy. For metastasized tumors, or for lesions, which cannot be removed surgically, chemotherapy is among the very few treatment options available. However, conventional chemotherapy may cause many severe side effects [40]. There are increasing numbers of developed nanocarriers for anticancer drug delivery in the aim to avoid side effects of the conventional chemotherapy. The most recent reports indicate that future nanomedicine may require new design principles toward an active targeting of nanocarriers [40-43]. Activetargeting based on ligand-receptor recognition may show better efficacy than passive targeting in human cancer therapy.

There are different ways of preparation of FA-targeted micelles - either solely from FAfunctionalized polymer [44] or with mixture of polymer without targeting moiety and functionalized polymer [45]. The second strategy seems reasonable taking into account economical aspect and the fact that studies confirmed the efficiency of addition of small amount 
of functional polymer to the drug carrier to obtain targeted delivery [45]. The dependency of the amount of folate on the micelle surface and their efficiency has been analyzed by Scarano W. et. al [46]. It was observed that in the case of small micelles the cytotoxicity of the encapsulated drug may be improved by increase of folate amount, while there is no difference in large micelles (over $100 \mathrm{~nm}$ ). A polymer to FA functionalized polymer mass ratio of 10:2 has been found to be effective by Zhang et al. [45]. We focused our study on analysis of composition of PLA-based micelles for anticancer therapy targeted to folic acid receptors. Three kinds of micelles were prepared from mixture of PLA $5000-\mathrm{PEG}_{5000}$ and PLA-Jeff-FA, PLA $_{3000}-$ PEG $_{5000}$ and PLA-Jeff-FA or PLA5000-PEG 5000 and PLA-PEG-FA. Micelles with PLAJeff-FA were obtained from its mixture with $\mathrm{PLA}_{3000}-\mathrm{PEG}_{5000}$ or PLA5000-PEG5000 to analyze the influence of PLA block length on micelles' properties. For comparison of the effect of the polymer with functional moiety, the PLA5000-PEG5000 was mixed either with PLA-Jeff-FA or PLA-PEG-FA.

The morphology of micelles was polymer-depended. The mixture of PLA ${ }_{5000} \mathrm{PEG}_{5000}$ and PLA-Jeff-FA or PLA ${ }_{5000} \mathrm{PEG}_{5000}$ and PLA-PEG-FA exclusively formed filomicelles, whereas PLA ${ }_{3000} \mathrm{PEG}_{5000}+$ PLA-Jeff-FA formed both filomicelles and spherical micelles (Fig. 2-3). With decrease of the PLA length and polymer hydrophobicity, the morphology turns from filomicelles to spherical micelles. Therefore, coexistence of several morphologies is a common phenomenon in transition regions [47]. Importantly, the morphology of all micelles did not change after drug loading (Fig. 3B), which is consistent with our previous study conducted on PLA-PEG micelles $[11,48]$. All the study has been conducted using lyophilized micelles, which enabled precise control of the micelle's concentration in drug loading study, drug release or cytotoxicity analysis. The storage stability of drug-loaded PLA-PEG lyophilized micelles has been confirmed [49]. 
The in vitro release study of E-29-diethoxyphosphoryl-28-O-propynoylbetulin from micellar systems revealed that the process proceeded in a prolonged manner up to $264 \mathrm{~h}$. However, some differences between polymers were observed (Fig. 5). In the group of micelles obtained from PLA-PEG and PLA-Jeff-FA, faster release was observed for copolymer with the shorter PLA chain (PLA $\left.3000 \mathrm{PEG}_{5000}+\mathrm{PLA}-\mathrm{Jeff}-\mathrm{FA}\right)$ compared to PLA $5000 \mathrm{PEG}_{5000}+\mathrm{PLA}-\mathrm{Jeff}$ FA filomicelles. The slowest rate of drug release was obtained for $\mathrm{PLA}_{5000} \mathrm{PEG}_{5000}+\mathrm{PLA}-\mathrm{PEG}-$ FA micelles.

FTIR analysis was conducted to evaluate drug-polymer interactions, which could explain the differences in the drug release properties (Fig. 6 - 8). Addition of drug to PLAPEG-FA increased the amount of bonded $\mathrm{C}=\mathrm{O}$ groups. This suggests interaction of $\mathrm{C}=\mathrm{O}$ ester groups with $\mathrm{OH}$ groups of E-29-diethoxyphosphoryl-28-O-propynoylbetulin, which may decrease the release rate from PLA5000 $P_{5 G}{ }_{500}+$ PLA-PEG-FA micelles. Comparison of the FTIR spectra of polymers (PLA-PEG-FA and PLA-Jeff-FA) and spectrum of FA (Fig. 8) demonstrated interactions between $\mathrm{C}=\mathrm{O}$ ester groups of $\mathrm{PLA}$ and $\mathrm{OH}, \mathrm{NH}$ and $\mathrm{NH}_{2}$ groups of FA in PLA-PEG-FA. The intramolecular interactions in PLA-PEG-FA were probably responsible for significant polymer precipitation during preparation of $\mathrm{PLA}_{5000} \mathrm{PEG}_{5000}+\mathrm{PLA}-$ PEG-FA micelles, which resulted in very low encapsulation efficiency (Table 3). These kinds of interactions between PLA and FA were not detected in PLA-Jeff-FA, due to shorter PLA block, which explained similar drug encapsulation efficiency and loading content in PLA $_{5000}$ PEG $_{5000}$ and PLA 5000 PEG $_{5000}+$ PLA-Jeff-FA micelles. Decrease of polymer hydrophobicity enabled to significantly increase the encapsulation efficiency in $\mathrm{PLA}_{3000} \mathrm{PEG}_{5000}+\mathrm{PLA}-\mathrm{Jeff}-\mathrm{FA}$ micelles in comparison to PLA $5000 \mathrm{PEG}_{5000}+\mathrm{PLA}-\mathrm{Jeff}-\mathrm{FA}$ micelles. Importantly, the differences are caused mainly by the length of PLA block, not by the kind of the FA-functionalized polymer. In fact, the $\mathrm{M}_{\mathrm{n}}$ of PLA was 1200 Da in PLA-Jeff-FA and 5000 Da in PLA-PEG-FA. Also, no intermolecular interactions were observed between 
PEG or Jeffamine and drug. Therefore, the hydrophobic block length may be used to control inter-and intramolecular interactions and in consequence, micelle's properties as drug encapsulation efficiency and release rate.

All kinds of drug-free micelles characterized biocompatibility, because they do not affect cell proliferation (Fig. 10). Otherwise, the drug loaded micelles decreased the number of breast cancer (SK-BR-3) cells (Fig. 9). The fragmentation of genomic DNA was analyzed for evaluation of the mechanism of cell death (Fig. 11). Both, free drug and drug loaded PLA $_{5000} \mathrm{PEG}_{5000}+$ PLA-Jeff-FA micelles induced significant DNA fragmentation. The largest amounts of DNA fragments were detected in the cytoplasmic fraction of cells treated with the drug at concentrations of $10 \mu \mathrm{M}$. Their lower concentrations at $30 \mu \mathrm{M}$ can be easily explained by increased permeability of cell membranes resulting from cell necrosis (secondary necrosis, following normal apoptotic death, or presumably primary necrosis). Permeable cell membrane in necrotic/late apoptotic cells allows nucleosomes to escape to the extracellular environment, and hence they are not available for the assay in cytoplasmic cell fraction [50, 51]. The strongest cytotoxic effect was observed for drug-loaded PLA5000 PEG $_{5000}+$ PLA-Jeff-FA micelles. The micelles displayed elongated shape, typical for short filomicelles (Fig. 2A). It has been reported that drug loaded short filomicelles $(\approx 180 \mathrm{~nm})$ exhibited the most efficient tumor accumulation and penetration in tumor tissues as well as the most effective suppression of the tumor growth as compared with drug loaded long filomicelles $(\approx 2.5 \mu \mathrm{m})$ and spherical micelles. Moreover, blood circulation studies showed a comparable circulation time for spherical micelles and short filomicelles, while long filomicelles were cleared quickly [3].

\section{Conclusions}

This work aimed to analyze the influence of the composition of PLA-based micelles on their drug encapsulation and release properties as well as cytotoxic activity against cancer cells. Micelles were obtained from combination of PLA-Jeff-FA with PLA5000-PEG5000 or PLA5000- 
PEG $_{5000}$. The third kind of analyzed micelles was obtained from the mixture of PLA-PEG-FA and PLA5000-PEG5000. All kinds of micelles provided release of E-29-diethoxyphosphoryl-28O-propynoylbetulin for over 264 hours. However, in vitro analysis revealed differences in micelle's drug loading and release properties.

FTIR analysis revealed inter- and intramolecular interactions, which may influence micelles' properties. Interaction of $\mathrm{C}=\mathrm{O}$ ester groups of PLA with $\mathrm{OH}$ groups of $\mathrm{E}-29$ diethoxyphosphoryl-28-O-propynoylbetulin may decrease the release rate from PLA $_{5000}$ PEG $_{5000}+$ PLA-PEG-FA micelles. However, in polymers with longer PLA blocks may be observed also interactions between $\mathrm{C}=\mathrm{O}$ ester groups of $\mathrm{PLA}$ and $\mathrm{OH}, \mathrm{NH}$ and $\mathrm{NH}_{2}$ groups of FA in PLA-PEG-FA, which may cause polymer precipitation during micelles' formation and decrease drug encapsulation efficiency. Two kinds of functionalized polymers were compared - PLA-Jeff-FA and PLA-PEG-FA. However, the differences are caused mainly by the length of the PLA block, not by the kind of the FA-functionalized polymer. Therefore, the length of a hydrophobic block may be used to control inter- and intramolecular interactions and in consequence, micelle's properties, e.g. drug encapsulation efficiency and release rate.

Last but not least, all kinds of drug-loaded micelles exhibited toxicity to ovarian cancer (SK-BR-3) cells at concentrations above $10 \mu \mathrm{M}$. The largest cytotoxic effect was observed for PLA $_{5000} \mathrm{PEG}_{5000}+$ PLA-Jeff-FA micelles with elongated shape, typical for short filomicelles (Fig. 2A). Therefore, these PLA based short filomicelles could be promising as nanocarrier of hydrophobic antitumor drugs.

Funding: The work is the result of the research project No. 2015/18/M/ST5/00060 funded by the National Science Centre.

Conflicts of Interest: The authors declare no conflict of interest. 


\section{References}

[1] J.B. Wolinsky, Y.L. Colson, M.W. Grinstaff, Local drug delivery strategies for cancer treatment: gels, nanoparticles, polymeric films, rods, and wafers, Journal of controlled release : official journal of the Controlled Release Society, 159 (2012) 14-26.

[2] P.R. Nair, C. Alvey, X. Jin, J. Irianto, I. Ivanovska, D.E. Discher, Filomicelles Deliver a ChemoDifferentiation Combination of Paclitaxel and Retinoic Acid That Durably Represses Carcinomas in Liver to Prolong Survival, Bioconjugate Chemistry, 29 (2018) 914-927.

[3] W. Ke, N. Lu, A.A.-W.M.M. Japir, Q. Zhou, L. Xi, Y. Wang, D. Dutta, M. Zhou, Y. Pan, Z. Ge, Length effect of stimuli-responsive block copolymer prodrug filomicelles on drug delivery efficiency, J Control Release, 318 (2020) 67-77.

[4] Y. Geng, P. Dalhaimer, S. Cai, R. Tsai, M. Tewari, T. Minko, D.E. Discher, Shape effects of filaments versus spherical particles in flow and drug delivery, Nature Nanotechnology, 2 (2007) 249-255.

[5] Y. Kim, P. Dalhaimer, D.A. Christian, D.E. Discher, Polymeric worm micelles as nano-carriers for drug delivery, Nanotechnology, 16 (2005) S484-S491.

[6] D. Li, Z. Tang, Y. Gao, H. Sun, S. Zhou, A Bio-Inspired Rod-Shaped Nanoplatform for Strongly Infecting Tumor Cells and Enhancing the Delivery Efficiency of Anticancer Drugs, Advanced Functional Materials, 26 (2016) 66-79.

[7] X. Liu, Y. Wang, P. Yun, X. Shen, F. Su, Y. Chen, S. Li, D. Song, Self-assembled filomicelles prepared from polylactide-poly(ethylene glycol) diblock copolymers for sustained delivery of cycloprotoberberine derivatives, Saudi Pharmaceutical Journal, 26 (2018) 342-348.

[8] J. Peng, J. Chen, F. Xie, W. Bao, H. Xu, H. Wang, Y. Xu, Z. Du, Herceptin-conjugated paclitaxel loaded PCL-PEG worm-like nanocrystal micelles for the combinatorial treatment of HER2positive breast cancer, Biomaterials, 222 (2019) 119420.

[9] A. Zajdel, A. Wilczok, K. Jelonek, M. Musial-Kulik, A. Forys, S.M. Li, J. Kasperczyk, Cytotoxic Effect of Paclitaxel and Lapatinib Co-Delivered in Polylactide-co-Poly(ethylene glycol) Micelles on HER-2-Negative Breast Cancer Cells, Pharmaceutics, 11 (2019).

[10] K. Jelonek, S.M. Li, X.H. Wu, J. Kasperczyk, A. Marcinkowski, Self-assembled filomicelles prepared from polylactide/poly(ethylene glycol) block copolymers for anticancer drug delivery, International Journal of Pharmaceutics, 485 (2015) 357-364.

[11] K. Jelonek, S.M. Li, B. Kaczmarczyk, A. Marcinkowski, A. Orchel, M. Musial-Kulik, J. Kasperczyk, Multidrug PLA-PEG filomicelles for concurrent delivery of anticancer drugs-The influence of drug-drug and drug-polymer interactions on drug loading and release properties, Int J Pharmaceut, 510 (2016) 365-374.

[12] K. Jelonek, A. Zajdel, A. Wilczok, M. Latocha, M. Musial-Kulik, A. Forys, J. Kasperczyk, Dualtargeted biodegradable micelles for anticancer drug delivery, Mater Lett, 241 (2019) 187-189. [13] J.K. Oh, Polylactide (PLA)-based amphiphilic block copolymers: synthesis, self-assembly, and biomedical applications, Soft Matter, 7 (2011) 5096-5108.

[14] T. Yasukawa, Y. Ogura, Y. Tabata, H. Kimura, P. Wiedemann, Y. Honda, Drug delivery systems for vitreoretinal diseases, Progress in retinal and eye research, 23 (2004) 253-281.

[15] Y. Hu, X. Jiang, Y. Ding, L. Zhang, C. Yang, J. Zhang, J. Chen, Y. Yang, Preparation and drug release behaviors of nimodipine-loaded poly(caprolactone)-poly(ethylene oxide)-polylactide amphiphilic copolymer nanoparticles, Biomaterials, 24 (2003) 2395-2404.

[16] L. Xu, Q. Bai, X. Zhang, H. Yang, Folate-mediated chemotherapy and diagnostics: An updated review and outlook, J Control Release, 252 (2017) 73-82. 
[17] C. Yue, P. Liu, M. Zheng, P. Zhao, Y. Wang, Y. Ma, L. Cai, IR-780 dye loaded tumor targeting theranostic nanoparticles for NIR imaging and photothermal therapy, Biomaterials, 34 (2013) 6853-6861.

[18] J.F. Ross, P.K. Chaudhuri, M. Ratnam, Differential regulation of folate receptor isoforms in normal and malignant tissues in vivo and in established cell lines. Physiologic and clinical implications, Cancer, 73 (1994) 2432-2443.

[19] S.D. Weitman, R.H. Lark, L.R. Coney, D.W. Fort, V. Frasca, V.R. Zurawski, B.A. Kamen, Distribution of the Folate Receptor Gp38 in Normal and Malignant-Cell Lines and Tissues, Cancer Research, 52 (1992) 3396-3401.

[20] Y.J. Lu, P.S. Low, Folate-mediated delivery of macromolecular anticancer therapeutic agents, Advanced Drug Delivery Reviews, 54 (2002) 675-693.

[21] B.A. Gruner, S.D. Weitman, The folate receptor as a potential therapeutic anticancer target, Investigational New Drugs, 16 (1998) 205-219.

[22] J.V. Brandt, R.D. Piazza, C.C. dos Santos, J. Vega-Chacón, B.E. Amantéa, G.C. Pinto, M. Magnani, H.L. Piva, A.C. Tedesco, F.L. Primo, M. Jafelicci, R.F.C. Marques, Synthesis and colloidal characterization of folic acid-modified PEG-b-PCL Micelles for methotrexate delivery, Colloids and Surfaces B: Biointerfaces, 177 (2019) 228-234.

[23] K. Jelonek, J. Kasperczyk, S. Li, T.H.N. Nguyen, A. Orchel, E. Chodurek, P. Paduszyński, M. Jaworska-Kik, E. Chrobak, E. Bębenek, S. Boryczka, M. Jarosz-Biej, R. Smolarczyk, A. Foryś, Bioresorbable filomicelles for targeted delivery of betulin derivative - In vitro study, Int J Pharmaceut, 557 (2019) 43-52.

[24] W. Agut, A. Brûlet, D. Taton, S. Lecommandoux, Thermoresponsive Micelles from Jeffamine-b-poly(I-glutamic acid) Double Hydrophilic Block Copolymers, Langmuir, 23 (2007) 11526-11533.

[25] A. Lu, E. Petit, S. Li, Y. Wang, F. Su, S. Monge, Novel thermo-responsive micelles prepared from amphiphilic hydroxypropyl methyl cellulose-block-JEFFAMINE copolymers, International Journal of Biological Macromolecules, 135 (2019) 38-45.

[26] J. Zhou, G. Romero, E. Rojas, S. Moya, L. Ma, C. Gao, Folic Acid Modified Poly(lactide-coglycolide) Nanoparticles, Layer-by-Layer Surface Engineered for Targeted Delivery, Macromolecular Chemistry and Physics, 211 (2010) 404-411.

[27] A. Sánchez-Ferrer, V.K. Kotharangannagari, J. Ruokolainen, R. Mezzenga, Thermoresponsive peptide-based triblock copolymer hydrogels, Soft Matter, 9 (2013) 4304-4311.

[28] G. Mocanu, M. Nichifor, L. Picton, E. About-Jaudet, D. Le Cerf, Preparation and characterization of anionic pullulan thermoassociative nanoparticles for drug delivery, Carbohydrate Polymers, 111 (2014) 892-900.

[29] L. Castan, C. José da Silva, E. Ferreira Molina, R. Alves Dos Santos, Comparative study of cytotoxicity and genotoxicity of commercial Jeffamines ${ }^{\circledR}$ and polyethylenimine in CHO-K1 cells, Journal of biomedical materials research. Part B, Applied biomaterials, 106 (2018) 742750.

[30] S.K. Krol, M. Kielbus, A. Rivero-Muller, A. Stepulak, Comprehensive Review on Betulin as a Potent Anticancer Agent, Biomed Research International, (2015).

[31] M.N. Laszczyk, Pentacyclic Triterpenes of the Lupane, Oleanane and Ursane Group as Tools in Cancer Therapy, Planta Medica, 75 (2009) 1549-1560.

[32] S. Boryczka, E. Bebenek, J. Wietrzyk, K. Kempinska, M. Jastrzebska, J. Kusz, M. Nowak, Synthesis, structure and cytotoxic activity of new acetylenic derivatives of betulin, Molecules, 18 (2013) 4526-4543. 
[33] E. Chrobak, M. Kadela-Tomanek, E. Bębenek, K. Marciniec, J. Wietrzyk, J. Trynda, B. Pawełczak, J. Kusz, J. Kasperczyk, E. Chodurek, P. Paduszyński, S. Boryczka, New phosphate derivatives of betulin as anticancer agents: Synthesis, crystal structure, and molecular docking study, Bioorganic Chemistry, 87 (2019) 613-628.

[34] S. Boryczka, E. Chrobak, A. Szymura, M. Latocha, M. Kadela, E. Bębenek, Acetylene derrivatives of betulin 30-phosphate with anti-tumor activity, method of their preparation and application. RP PatentPL 230002B1 filled 14 August 2015, issued 13 April 2018., in, 2018.

[35] E. Chrobak, E. Bębenek, M. Kadela-Tomanek, M. Latocha, C. Jelsch, E. Wenger, S. Boryczka, Betulin Phosphonates; Synthesis, Structure, and Cytotoxic Activity, Molecules (Basel, Switzerland), 21 (2016) 1123.

[36] L. Szoka, E. Karna, K. Hlebowicz-Sarat, J. Karaszewski, S. Boryczka, J.A. Palka, Acetylenic derivative of betulin induces apoptosis in endometrial adenocarcinoma cell line, Biomed. Pharmacother., 95 (2017) 429-436.

[37] A. Orchel, A. Kulczycka, E. Chodurek, E. Bebenek, P. Borkowska, S. Boryczka, J. Kowalski, Z. Dzierzewicz, Influence of betulin and 28-O-propynoylbetulin on proliferation and apoptosis of human melanoma cells (G-361), Postepy Hig Med Dosw (Online), 68 (2014) 191-197.

[38] E. Bebenek, M. Kadela-Tomanek, E. Chrobak, J. Wietrzyk, J. Sadowska, S. Boryczka, New acetylenic derivatives of betulin and betulone, synthesis and cytotoxic activity, Med. Chem. Res., 26 (2017) 1-8.

[39] A. Orchel, E. Chodurek, M. Jaworska-Kik, P. Paduszynski, A. Kaps, E. Chrobak, E. Bebenek, S. Boryczka, P. Borkowska, J. Kasperczyk, Anticancer Activity of the Acetylenic Derivative of Betulin Phosphate Involves Induction of Necrotic-Like Death in Breast Cancer Cells In Vitro, Molecules, 26 (2021).

[40] S.K. Golombek, J.-N. May, B. Theek, L. Appold, N. Drude, F. Kiessling, T. Lammers, Tumor targeting via EPR: Strategies to enhance patient responses, Advanced Drug Delivery Reviews, 130 (2018) 17-38.

[41] Y. Zhu, J. Feijen, Z. Zhong, Dual-targeted nanomedicines for enhanced tumor treatment, Nano Today, 18 (2018) 65-85.

[42] F. Danhier, To exploit the tumor microenvironment: Since the EPR effect fails in the clinic, what is the future of nanomedicine?, J Control Release, 244 (2016) 108-121.

[43] Y.S. Youn, Y.H. Bae, Perspectives on the past, present, and future of cancer nanomedicine, Advanced Drug Delivery Reviews, 130 (2018) 3-11.

[44] D. Luong, P. Kesharwani, H.O. Alsaab, S. Sau, S. Padhye, F.H. Sarkar, A.K. Iyer, Folic acid conjugated polymeric micelles loaded with a curcumin difluorinated analog for targeting cervical and ovarian cancers, Colloids and Surfaces B: Biointerfaces, 157 (2017) 490-502.

[45] J. Zhang, X. Zhao, Q. Chen, X. Yin, X. Xin, K. Li, M. Qiao, H. Hu, D. Chen, X. Zhao, Systematic evaluation of multifunctional paclitaxel-loaded polymeric mixed micelles as a potential anticancer remedy to overcome multidrug resistance, Acta Biomater, 50 (2017) 381-395.

[46] W. Scarano, H.T.T. Duong, H. Lu, P.L. De Souza, M.H. Stenzel, Folate Conjugation to Polymeric Micelles via Boronic Acid Ester to Deliver Platinum Drugs to Ovarian Cancer Cell Lines, Biomacromolecules, 14 (2013) 962-975.

[47] K. Rajagopal, A. Mahmud, D.A. Christian, J.D. Pajerowski, A.E.X. Brown, S.M. Loverde, D.E. Discher, Curvature-Coupled Hydration of Semicrystalline Polymer Amphiphiles Yields flexible Worm Micelles but Favors Rigid Vesicles: Polycaprolactone-Based Block Copolymers, Macromolecules, 43 (2010) 9736-9746. 
[48] K. Jelonek, S.M. Li, J. Kasperczyk, X.H. Wu, A. Orchel, Effect of polymer degradation on prolonged release of paclitaxel from filomicelles of polylactide/poly(ethylene glycol) block copolymers, Mat Sci Eng C-Mater, 75 (2017) 918-925.

[49] A. Zajdel, A. Wilczok, K. Jelonek, M. Musial-Kulik, A. Forys, S. Li, J. Kasperczyk, Cytotoxic Effect of Paclitaxel and Lapatinib Co-Delivered in Polylactide-co-Poly(ethylene glycol) Micelles on HER-2-Negative Breast Cancer Cells, Pharmaceutics, 11 (2019).

[50] S. Rello, J.C. Stockert, V. Moreno, A. Gamez, M. Pacheco, A. Juarranz, M. Canete, A. Villanueva, Morphological criteria to distinguish cell death induced by apoptotic and necrotic treatments, Apoptosis, 10 (2005) 201-208.

[51] M. Zaklos-Szyda, N. Pawlik, D. Polka, A. Nowak, M. Koziolkiewicz, A. Podsedek, Viburnum opulus Fruit Phenolic Compounds as Cytoprotective Agents Able to Decrease Free Fatty Acids and Glucose Uptake by Caco-2 Cells, Antioxidants (Basel), 8 (2019). 